\title{
O IMPACTO DO PRONAF SOBRE A SUSTENTABILIDADE AGRÍCOLA DE AGRICULTORES FAMILIARES NA MICRORREGIÃO DO VALE DO MÉDIO CURU, NO ESTADO DO CEARÁ
}

\author{
Ana Tereza Bittencourt Passos * \\ Ahmad Saeed Khan ${ }^{\dagger}$
}

\begin{abstract}
Resumo
O estudo tem por objetivo avaliar o impacto do PRONAF sobre a sustentabilidade agrícola de agricultores familiares por meio do propensity score matching. Os dados são oriundos de pesquisa direta com beneficiários e não beneficiários. Os resultados com pareamento demonstram que os beneficiários apresentam sustentabilidade agrícola superior aos não beneficiários. O PRONAF, entretanto, traz impactos positivos para as gestões econômica e social da propriedade, bem como para a receita agrícola anual, embora tenha se mostrado ineficaz para incentivar a adoção de práticas agrícolas sustentáveis, comprometendo a gestão ambiental da propriedade e a sustentabilidade agrícola em longo prazo.
\end{abstract}

Palavras-chave: políticas públicas, PRONAF, sustentabilidade agrícola, agricultura familiar, propensity score matching.

\begin{abstract}
The study aims to evaluate the impact of PRONAF on agricultural sustainability of family farming through propensity score matching. The data were obtained by interviewing beneficiaries and non-beneficiaries of the program. The results show that paired beneficiaries have higher agricultural sustainability as compared to non-beneficiaries. However, PRONAF has positive impacts on economic and social management of the property, and the annual farm income. It has been ineffective to encourage the adoption of sustainable agricultural practices, compromising the environmental management of the property and the long-run agricultural sustainability.
\end{abstract}

Keywords: public policies, PRONAF, agricultural sustainability, family farming, propensity score matching.

JEL classification: Q56, Q58.

DOI: http://dx.doi.org/10.11606/1980-5330/ea169979

\footnotetext{
* Universidade Federal Rural do Semiárido (UFERSA), Departamento de Ciências Humanas (DCH), Mossoró (RN), Brasil. E-mail: anabittencourtpassos@gmail.com

${ }^{\dagger}$ Universidade Federal do Ceará (UFC), Departamento de Economia Agrícola, Fortaleza (CE), Brasil; Universidade Regional do Cariri, Departamento de Ciências Econômicas, Crato (CE), Brasil. E-mail: saeed@ufc.br
} 


\section{Introdução}

As políticas públicas expressam as ações do Estado no exercício do poder político, objetivando promover correções para imperfeições que impedem ou dificultam a distribuição igualitária de benefícios econômicos ou sociais. No Brasil, as políticas públicas, até os anos de 1990, eram de caráter desenvolvimentista e voltavam-se, prioritariamente, à política agrícola, apresentando como principais instrumentos o crédito rural, o seguro agrícola e os preços mínimos.

Em 1996, foi criado, oficialmente, o Programa Nacional de Agricultura Familiar (PRONAF), destinado à concessão de crédito rural em condições especiais para os agricultores familiares, até então excluídos do sistema financeiro tradicional.

O PRONAF representa um marco importante na política agrícola nacional, não apenas por ser o primeiro programa voltado, especificamente, para esse segmento (Schneider et al. 2004), como também pelo reconhecimento do Estado à agricultura familiar e à necessidade de delinear políticas diferenciadas de desenvolvimento rural (Grisa 2010).

Ao longo do tempo, o PRONAF transita por modificações importantes, buscando atender a heterogeneidade dos agricultores familiares das distintas regiões geográficas e às transformações impostas por novos paradigmas socioeconômicos e ambientais, mantendo, entretanto, suas características primordiais de atendimento à agricultura familiar.

Nas regiões mais carentes, como no Nordeste, o PRONAF assume maior expressividade em função da grande abrangência que o Programa alcança, dos elevados recursos financeiros envolvidos e da relevância socioeconômica exercida pela agricultura familiar na segurança alimentar, geração de emprego e renda e dinamização das economias locais (Mattei 2005).

No Estado do Ceará, dos 341.509 estabelecimentos agropecuários classificados como de agricultura familiar, 74,4\%, ou 254.062 desses, enquadram-se no grupo B do PRONAF, caracterizado como o segmento de agricultores mais pobres (IPEA 2013).

O grupo B do PRONAF, explica Del Grossi (2011), é representando por agricultores familiares, proprietários ou não, residentes na propriedade ou em local próximo, que possuem terra com áreas inferiores a quatro módulos fiscais e são exploradas com base no trabalho familiar, sem uso de qualquer tipo de empregado permanente.

Não obstante a longevidade, magnitude e expressividade do Programa, não são incomuns na literatura críticas rigorosas, principalmente em relação à desigualdade nos valores e na distribuição do crédito entre as regiões geográficas (Aquino \& Schneider 2010, Souza et al. 2011, Gazolla \& Schneider 2013, Souza et al. 2014, Grisa et al. 2014). O PRONAF, no entanto, como programa de Estado de incentivo à produção agropecuária, ressente-se de avaliações em relação à sustentabilidade agrícola dos agricultores familiares, já que o grande desafio das próximas décadas é elevar a produção agropecuária sem comprometer os recursos naturais.

Na visão de Guanziroli (2007), a maioria das pesquisas até então desenvolvidas sobre o Programa objetiva muito mais uma avaliação de processo do que uma mensuração de impacto. Aliada a isso, a análise mais sistemática do PRONAF torna-se imperiosa (Chaddad et al. 2006) para uma avaliação imparcial dos impactos econômicos e sociais. Argúem, ainda, esses estudiosos o 
fato de que a ausência de indicadores e instrumentos de avaliação pode conduzir à falta de transparência e de legitimidade das ações do Programa. Na literatura da avaliação de impacto, estudos sobre o PRONAF são ainda muito restritos (Feijó 2001, Mattei 2005, Magalhães et al. 2006, Neder \& Buainain 2012, Moreira et al. 2014) e, inexistem em relação à sustentabilidade agrícola de agricultores familiares embora este tema esteja presente na agenda de muitas instituições de pesquisa.

A agricultura tem papel importante na entrega de alimentos e outros bens destinados aos próprios agricultores e aos mercados, e a agricultura familiar se insere nesse contexto, além de contribuir para dinamizar a economia dos territórios rurais. Tanto é assim que dos R\$190,25 bilhões destinados ao Plano Safra da Agricultura Familiar 2017/2018, R\$ 30 bilhões são destinados ao PRONAF (Brasil 2017).

Em razão da relevância desse segmento e do significativo volume de recursos envolvidos, a avaliação de impacto do PRONAF justifica-se como instrumento capaz de identificar o efeito do Programa e em que medida o efeito pode ser atribuído efetivamente a este e não a outras causas. Dessa forma, a hipótese assumida no estudo é a de que o PRONAF apresenta impactos positivos à sustentabilidade agrícola dos agricultores familiares no Estado do Ceará.

Espera-se que o estudo possa preencher a lacuna de avaliação de impacto do Programa e oferecer subsídios para os decisores de políticas públicas, com vistas a aprimorar sua operacionalização e contribuir para a formulação de políticas agrícolas de incentivo à sustentabilidade agrícola dos agricultores familiares.

\section{Referencial Teórico}

\subsection{A sustentabilidade e a sustentabilidade agrícola}

O conceito de sustentabilidade auferiu popularidade e proeminência desde a divulgação do Relatório Bruntdland, em 1986 (WCED), e após editada a Agenda 21, da Conferência das Nações Unidas sobre o Meio Ambiente e Desenvolvimento (CNUMAD), em 1992, ao mesmo tempo em que desperta a comunidade internacional para o uso racional dos recursos naturais.

Sustentabilidade envolve um conceito amplo. Ainda que seu domínio, antes reivindicado pelas Ciências Biológicas e Ambientais, tenha se democratizado, o conceito hoje integra outras áreas do conhecimento, justificando a ideia de que esta definição (White 2013) significa coisas diferentes para pessoas distintas, originando, assim, inúmeras definições. Essa diversidade, ressaltam Van Calker et al. (2005), é explicada em grande parte pela posição e opinião do usuário.

Estudiosos como Hansen \& Jones (1996), definem a sustentabilidade como a capacidade de um sistema para continuar no futuro. Para esses autores, o conceito pode ser aplicado a qualquer sistema dinâmico, já que a capacidade de continuar não se emprega a um sistema estático. Para Waas et al. (2011), o conceito é caracterizado pelo que poderia ser chamado de "flexibilidade interpretativa" e permite diversas visualizações e interpretações à coexistência, dentro dos limites de sua interpretação. Explicam os autores, entretanto, que a sustentabilidade não é um "destino final", mas uma viagem longa orientada para o destino. Ainda que, às vezes, argumente-se que a sustentabilidade, por 
definição, nunca possa ser alcançada, os autores destacam que esse raciocino pode ser uma armadilha e um argumento para escapar do compromisso social. Ressaltam, porém, que a sustentabilidade pode e deve ser alcançada, e, em última análise, depende de vontade política e social, devendo ser considerada como uma busca contínua por um delicado equilíbrio em um ambiente dinâmico.

A sustentabilidade agrícola é um desdobramento do conceito original e, tal como este, também denota muitas interpretações. A multiplicidade de conceitos de sustentabilidade agrícola, entretanto, na visão de Frater \& Franks (2013), mostra a falta de compreensão de como as funções dos ecossistemas são afetadas pela agricultura em curto e longo prazos. Essa flexibilidade conceitual, evidenciam os autores, tem benefícios, uma vez que favorece a interpretação mais ampla.

Em sistemas agrícolas, Pretty (2006), destaca que a sustentabilidade incorpora os conceitos de resiliência (a capacidade dos sistemas de resistir a choques e tensões) e a persistência (a capacidade dos sistemas para continuar por um longo período), tendo como princípios-chave: i) integrar processos biológicos e ecológicos na produção de alimentos; ii) minimizar o uso de insumos não renováveis que causem danos para o meio ambiente ou para a saúde dos agricultores e consumidores; iii) fazer uso produtivo do conhecimento e habilidades dos agricultores para melhorar a autoestima e iv) fazer uso produtivo das capacidades das pessoas para trabalhar em conjunto, com o intuito de resolver problemas comuns na agricultura ou nos recursos naturais. Na visão do autor, o conceito de sustentabilidade agrícola não significa excluir quaisquer tecnologias ou práticas por motivos ideológicos. Se uma tecnologia ajuda a melhorar a produtividade dos agricultores e não causa danos indevidos para o ambiente, é susceptível de ter alguns benefícios de sustentabilidade.

Na concepção de Schaller (1993), o conceito de agricultura sustentável sugere não apenas um destino para a agricultura, mas também as práticas agrícolas, em particular, que poderiam conduzir a agricultura para esse destino. Essas práticas, destaca o autor, não podem ser definidas com facilidade, simplesmente porque ninguém sabe, precisamente, quais práticas e em que circunstâncias ou locais são mais sustentáveis.

Enfatizando a importância das práticas agrícolas na sustentabilidade agrícola, Tilman et al. (2002), evidenciam a ideia de que a agricultura sustentável representa a adoção de práticas que atendem as necessidades sociais atuais e futuras de alimentos e fibras, serviços dos ecossistemas e de uma vida saudável e, quando bem conduzidas, essas práticas determinam o nível de produção alimentar e o estado do ambiente.

Entrementes, na perspectiva de Häni et al. (2003), a agricultura sustentável requer a adoção de práticas produtivas, competitivas e eficientes, visando a proteger e melhorar o ambiente e o ecossistema global.

A ênfase imprimida às práticas agrícolas no estudo da sustentabilidade agrícola (Hansen \& Jones 1996, Pretty 2006, De Koeijer et al. 1999, Tilman et al. 2002), conduz à adoção, como ponto de partida, na própria fazenda, já que é esse o local onde se concentram todos os atributos ambientais, econômicos e sociais da exploração agrícola. Em razão, todavia, da multifuncionalidade da agricultura, reconhecida por muitos estudiosos (Sands \& Podmore 2000, Binder et al. 2012, Singh et al. 2012, Rinne et al. 2013, Ryan et al. 2014, Reidsma et al. 2015), justifica-se a necessidade de se proceder a uma abordagem holística de integração ambiental, econômica e social, áreas essas que, 
de modo consensual, compõem na literatura especializada as dimensões da sustentabilidade agrícola.

Não obstante a influência individual dos diversos fatores incertos nessas dimensões, muitos estudiosos (Zaccagnini 2001, Dumanski et al. 1998, Van Calker et al. 2005) ressaltam que o mais importante é a interação entre eles, já que é isto que irá determinar se terão ou não um uso sustentável da terra.

Na literatura nacional, os estudos sobre a sustentabilidade agrícola são muito exíguos, o que dificulta o desenvolvimento de novas ideias e pesquisas. Focando nesse tema, foi identificado apenas o estudo de Gomes et al. (2009), que usou modelos de Análise de Envoltória de Dados (Data Envelopment Analysis - DEA), para medir a sustentabilidade de produtores agrícolas em Machadinho do Oeste ( $\mathrm{RO})$. Os resultados sugerem que não há sustentabilidade nem do ponto de vista econômico nem do ambiental.

\subsection{Gestão da unidade de produção agrícola e a tomada de decisões}

As decisões de produção do agricultor, argúem Allen et al. (1991), determinam a diversidade e a qualidade dos alimentos disponíveis aos consumidores, o tamanho das propriedades e as tecnologias, que têm sido associadas ao vigor econômico e social das comunidades, ao mesmo tempo em que a sociedade determina o que é possível explorar no contexto de propriedade.

O conceito de gestão sustentável da terra é cada vez mais aplicado às políticas e atividades da agricultura (Dumanski et al. 1998), de modo a melhorar as políticas e funções ambientais dos recursos naturais.

Aliadas às políticas e práticas da gestão, a disponibilidade de recursos financeiros favorece a capacidade de adquirir tecnologias e de escolher o tipo, o nível e a intensidade de uso de insumos e dos fatores de produção. Dessa forma, se depreende que a relevância do crédito agrícola, ao permitir que esses efeitos sejam expandidos, enseja a elevação da produtividade e, consequentemente, da renda e da geração de emprego agrícola.

O crédito, entretanto, não basta por si, pois o funcionamento da empresa rural, destaca Lourenzani (2006), resulta de uma estrutura complexa, composta de variáveis distintas e interdependentes. Ademais, a gestão da empresa rural, (Norman \& Dixon 1995, Santos \& Marion 1996, Zaccagnini 2001) está sujeita à influência de inúmeros fatores internos e externos que interferem no alcance da sustentabilidade agrícola. Na visão de Dumanski (1997), entretanto, o conceito de gestão sustentável da terra está sendo cada vez mais aplicado às decisões da gestão das terras.

A busca da sustentabilidade agrícola, ressalta Schaller (1993), é limitada quase inteiramente à investigação das práticas agrícolas potencialmente mais sustentáveis, uma vez que os agricultores são os principais gerentes das terras utilizáveis. Entretanto, os impactos ambientais prejudiciais dessas práticas representam custos não normalmente mensuráveis e, muitas vezes, não influenciam o agricultor ou as escolhas sociais sobre os métodos de produção.

Outros estudiosos (Tilman et al. 2002) compartilham dessa ideia e salientam que as boas práticas de gestão da propriedade podem melhorar a sustentabilidade agrícola, mediante o emprego de uma variedade de estratégias da gestão. Se utilizadas incorretamente, contudo, as práticas agrícolas podem reduzir a capacidade dos ecossistemas e dos serviços por eles prestados.

Na literatura internacional, são frequentes os estudos que adotam a avaliação da sustentabilidade agrícola no plano de fazenda ou de produtor (Vilain 
2008, Gómez-Limón \& Sanchez-Fernandez 2010). Entretanto, dentre estes, destaca-se o de Rigby et al. (2001), que usa as práticas agrícolas como indicador da dimensão ambiental, tal como adotado neste estudo.

\section{Metodologia}

\subsection{Tipo de pesquisa e natureza dos dados}

O presente estudo caracteriza-se como pesquisa do tipo quase-experimental, uma vez que permite a comparação entre as condições de tratamento e não tratamento, com grupos não equivalentes ou com os mesmos indivíduos, desde que realizada antes do tratamento, e possibilita, ainda, a análise de causaefeito, razão de ser da conveniência de sua aplicação (Gil 2008).

Os dados utilizados no estudo são de origem primária, resultantes da aplicação de questionários semiestruturados, para coleta de informações junto aos agricultores familiares nos municípios selecionados.

\subsection{Público-alvo, área de estudo e tamanho da amostra}

O público-alvo da pesquisa são os agricultores familiares, divididos em dois grupos - o de agricultores familiares beneficiários do PRONAF B e o de agricultores não beneficiários - de acordo com o modelo adotado.

A área objeto deste estudo compreende os Municípios de São Luís do Curu e Pentecoste, inseridos na Microrregião do Vale do Médio Curu, no Estado do Ceará.

Na seleção dos municípios, foram considerados fatores determinantes a maior concentração de agricultores familiares, beneficiários do PRONAF, e a existência de semelhança entre eles, tanto em relação às características socioeconômicas e culturais, quanto no concernente ao valor do Índice de Desenvolvimento Humano Municipal - IDHM para 2013, que, para São Luís do Curu, é de 0,62, enquanto para Pentecoste, é de 0,629 (PNUD, 2013).

A amostra foi selecionada de maneira não aleatória, objetivando atender os pressupostos básicos do propensity score matching, que requer que a participação no programa independa dos resultados e seja condicional nas covariáveis, e a presença de um suporte comum, de maneira a evitar o viés no pareamento.

Na determinação da amostra, considerando-se que a população pesquisada é finita (Cochran 1977), foi aplicada a equação (1).

$$
n=\frac{Z^{2} \cdot p \cdot q \cdot N}{e^{2}(N-1)+Z^{2} \cdot p \cdot q}
$$

em que: $\mathrm{n}=$ tamanho da amostra; $\mathrm{Z}=$ Valor correspondente ao nível de confiança escolhido $(5 \%$ e $Z=1,96) ; p=$ percentagem com a qual o fenômeno se verifica $(0,5) ; \mathrm{q}=$ percentagem complementar $(0,5) ; \mathrm{N}=$ tamanho da população (estabelecimentos de agricultura familiar (1.498); e = erro não amostral (7\%).

Para a determinação do tamanho da amostra considerou-se a população de 1.498 estabelecimentos de agricultores familiares dos Municípios de São Luís do Curu e Pentecoste, (Brasil 2010), sendo que, destes, apenas 34,4\%, isto é, 516, são beneficiários do PRONAF. Aplicando-se a equação (1), foi calculada 
a amostra de 173 agricultores familiares. Pelo fato de apenas $34,4 \%$, desse total participar do Programa, isso significa que a amostra tem 60 beneficiários e 113 não beneficiários, número esse acrescido para 125, para melhorar o pareamento do modelo. A amostra total corresponde, assim, a 185 agricultores familiares, sendo 60 beneficiários e 125 não beneficiários do PRONAF.

\subsection{Tratamento dos dados}

Para proceder à análise estatística dos dados, foram usados o Teste de Levene, destinado a averiguar a homogeneidade das variâncias dos grupos de beneficiários e não beneficiários do Programa, e o Teste " $t$ " de Student, para comparação de médias desses grupos, recorrendo-se, ao programa Statistical Package for Social Science-SPSS.

\subsection{Métodos analíticos}

Para alcançar o objetivo do estudo, procedeu-se, inicialmente, à constituição dos índices e indicadores para representar as dimensões ambiental, econômica e social da sustentabilidade agrícola com dados não pareados, constantes do Apêndice A. A seguir, foi aplicado o método do Propensity Score Matching, com a utilização do programa Stata.

\section{O Índice de Sustentabilidade Agrícola (ISA)}

A sustentabilidade agrícola dos agricultores familiares beneficiários e não beneficiários do PRONAF é mensurada por meio do Índice de Sustentabilidade Agrícola (ISA), que corresponde à média aritmética dos Índices da Gestão Ambiental (IGA), Gestão Econômica (IGE) e Gestão Social (IGS). O ISA varia de zero a um. Quanto mais próximo de um, mais elevada é a sustentabilidade agrícola e quanto mais próximo de zero, menor é a sustentabilidade agrícola. Para avaliar o nível de sustentabilidade agrícola de beneficiários e não beneficiários do PRONAF, foram adotados os limites de Damasceno et al. (2011), compreendendo: i. baixo nível de sustentabilidade agrícola $-0,0 \leq I S A<0,5$; ii. médio nível de sustentabilidade agrícola $-0,5 \leq I S A<0,8$, e iii. alto nível de sustentabilidade agrícola - ISA $\geq 0,8$.

\section{O Índice da Gestão Ambiental (IGA)}

O Índice da Gestão Ambiental (IGA), tem por objetivo analisar a sustentabilidade ambiental de agricultores familiares beneficiários e não beneficiários do PRONAF, a partir do uso de práticas agrícolas, de acordo com os seguintes indicadores: práticas de preparo do solo, de plantio, de pós-plantio, de combate às pragas e recebimento dos serviços de assistência técnica e extensão rural, que integram o conjunto de indicadores deste índice. A formulação do IGA foi adaptada de Damasceno et al. (2011).

Matematicamente, o IGA é definido de acordo com a equação (2).

$$
I G A=\frac{1}{d} \sum_{k=1}^{d} C_{k}
$$


e a participação de cada indicador na composição do IGA é dada pela Equação (3).

$$
C_{k}=\frac{1}{m} \sum_{j=1}^{m}\left[\frac{1}{n} \sum_{i=1}^{n}\left(\frac{E_{i j}}{E_{\max i}}\right)\right]
$$

em que: $E_{i j}=$ escore da i-ésima variável do indicador " $k$ " obtido pelo j-ésimo agricultor familiar; $\operatorname{Emax}_{i}=$ escore máximo da i-ésima variável do indicador " $k$ "; $i=1, \ldots, n$ (variáveis que compõem o indicador " $k$ "); $j=1, \ldots, m$ (agricultores familiares); $k=1, \ldots, d$ (indicadores que compõem o IGA).

Na elaboração dos Índices da Gestão Econômica (IGE) e da Gestão Social (IGS), é aplicada a mesma sistemática às variáveis e indicadores constantes do Apêndice A.

Na composição do Índice da Gestão Econômica (IGE) são considerados os indicadores de eficiência financeira, organização da propriedade e resiliência econômica (este último, adaptado de Lopes (2001)).

O Índice da Gestão Social, foi mensurado com base na concepção de Goodland (1995), que inclui nessa dimensão, a coesão social. Para as Nações Unidas $(2007,2010)$, a coesão social representa o debate entre os instrumentos de inclusão e exclusão social e as respostas e percepções dos indivíduos em face do funcionamento desses mecanismos. Integram esse índice os indicadores de confiança institucional, organização de mercados, sentimento de pertencimento, reforço de laços e valores e participação social em defesa de seus interesses.

O conjunto de índices e indicadores que compõem o Índice de Sustentabilidade Agrícola, (descrito no Apêndice A), bem como a Receita Agrícola Anual, resultante exclusivamente, da produção agrícola, correspondem às variáveis independentes a serem usadas na regressão logit, que antecede a aplicação do modelo do escore de propensão.

\section{Efeitos das características socioeconômicas no acesso ao PRONAF}

A propensão de o agricultor ser incluído no PRONAF pode ser avaliada, conforme Passos (2014), considerando as variáveis representativas das características dos agricultores familiares, por via do modelo de regressão logit a seguir descrito:

$$
\begin{gathered}
Y_{i}^{*}=\beta_{0}+\beta_{1} i d a d+\beta_{2} e s t c+\beta_{3} \text { arec }+\beta_{4} n h d f+\beta_{5} e s c o+\beta_{6} \text { sale }+ \\
\beta_{7} \text { ano }+\beta_{8} \text { agud }+\beta_{9} c o n m+\beta_{10} t i p c+\beta_{11} n u m c+\beta_{12} i g p 2+u_{i}
\end{gathered}
$$

em que: $Y_{i}^{*}$ é uma variável binária que expressa se o agricultor familiar é beneficiário do PRONAF (igual a 1) 1 , ou se não é beneficiário do Programa (igual a zero). Os $\beta_{s}$ são os parâmetros da regressão associados às variáveis representativas das características dos agricultores (Tabela 1), e $u_{i}$ corresponde ao termo do erro aleatório. 
Tabela 1: Variáveis explicativas aplicadas ao modelo logit para beneficiários e não beneficiários do PRONAF, na microrregião do Vale do Médio Curu, no Estado do Ceará

\begin{tabular}{|c|c|c|c|}
\hline Discriminação & Abreviatura & Classificação & $\begin{array}{l}\text { Variáveis e sua Operacionaliza- } \\
\text { ção }\end{array}$ \\
\hline Idade & idad & escalar & Anos \\
\hline Estado Civil & estci & ordinal & $\begin{array}{l}1=\text { Solteiro; } 2 \text { = Casado; } 3= \\
\text { Viúvo ou Divorciado; } 4=\text { União } \\
\text { Estável }\end{array}$ \\
\hline Área Colhida (ha) & arec & escalar & hectares \\
\hline Número Homens-Dia Familiar & nhdf & escalar & unidade \\
\hline Escolaridade & esco & escalar & $\begin{array}{l}0=\text { Sem instrução; } 1=\text { Funda- } \\
\text { mental; } 2=\text { Médio; } 3=\text { Superior. }\end{array}$ \\
\hline Sabe ler e escrever & sale & binária & 0 = Não; 1 = Sim. \\
\hline Tempo de trabalho na propriedade & anop & ordinal & $\begin{array}{l}1=\text { menos de } 5 \text { anos; } 2=\text { de } 6 \text { a } \\
10 \text { anos; } 3=\text { de } 11 \text { a } 15 \text { anos; } 4= \\
\text { mais de } 15 \text { anos. }\end{array}$ \\
\hline $\begin{array}{l}\text { A água disponível na propriedade } \\
\text { é }\end{array}$ & agud & ordinal & $\begin{array}{l}\text { 1=é suficiente só para uso do- } \\
\text { méstico; } 2=\text { é suficiente para } \\
\text { todo uso }\end{array}$ \\
\hline Condições de moradia & conm & binária & $\begin{array}{l}0=\text { Alugada ou Cedida; } 1 \text { = Pró- } \\
\text { pria }\end{array}$ \\
\hline Tipo construção da moradia & tipc & binária & $0=$ Taipa; 1 = Alvenaria \\
\hline Número cômodos da moradia & numc & escalar & unidade \\
\hline $\begin{array}{l}\text { Indice propensão à sustentabili- } \\
\text { dade agrícola (isa2) }\end{array}$ & isa 2 & binária & $\begin{array}{l}=0, \text { se isa } 2<0,5 \\
=1, \text { se } 0,5 \leq \text { isa } 2 \leq 1,0\end{array}$ \\
\hline
\end{tabular}

Fonte: Elaboração dos autores

\section{O Pareamento pelo escore de propensão}

A avaliação de políticas públicas, em geral, está condicionada à mensuração de seus impactos sobre uma unidade de observação, ou seja, um grupo de beneficiários.

O tipo da avaliação denominada de "avaliação de impacto", destina-se a definir de maneira mais ampla, se um determinado programa teve os efeitos desejados sobre os indivíduos e se estes são atribuíveis à intervenção do Programa, já que podem existir outros fatores correlacionados com os resultados, mas que não foram causados pelo Programa.

Para avaliar os impactos do PRONAF sobre a sustentabilidade agrícola dos agricultores familiares (Passos 2014), foi utilizada a metodologia do matching ou pareamento, a que se recorre bastante na literatura específica para estimar os efeitos causais do Programa, com base em uma amostra de não beneficiários cujas características observáveis são semelhantes às encontradas no grupo de tratamento (agricultores familiares beneficiários do PRONAF).

$\mathrm{Na}$ constituição do grupo de controle (agricultores familiares não beneficiários do PRONAF), muitos fatores podem afetar a confiabilidade dos resultados. Esses fatores, são os chamados "vieses de seleção", que resultam de possíveis diferenças entre as características observáveis e não observáveis deste grupo em relação às encontradas no grupo - tratamento. O método do Propensity Score Matching, desenvolvido por P. R. Rosenbaum \& Rubin (1983), visa a solucionar a dificuldade de se dispor de informações sobre o mesmo indivíduo antes e depois do acesso ao Programa e assim, resolver o problema do "viés de seleção".

Com o objetivo de vencer as dificuldades na constituição desses grupos, Roy (1951) e Rubin (1974) propuseram a substituição do grupo de controle, por indivíduos que efetivamente não recebem o tratamento, por intermédio de uma variável dummy, que assume o valor igual a 1 se o indivíduo é beneficiário 
do Programa, e valor 0 para o não beneficiário. Foi designado por $Y_{i(1)}$ o valor da variável de resultado para o agricultor familiar $i$ do grupo de beneficiários, enquanto $Y_{i(0)}$ representa o valor da mesma variável, caso o agricultor familiar esteja no grupo de controle (não beneficiários).

Com efeito, o resultado do Programa $(Y)$ sobre cada agricultor familiar (i), em linguagem algébrica, corresponde, a:

$$
\pi_{i}=Y_{i(1)}-Y_{i(0)}
$$

O impacto médio do Programa para o agricultor familiar $i$ pode ser representado pela equação:

$$
\pi_{i}=E\left[Y_{i(1)} \mid D_{i}=1\right]-E\left[Y_{i(0)} \mid D_{i}=1\right]
$$

Como não se dispõe de informações do beneficiário antes e depois da implantação do Programa, os agricultores desse grupo são substituídos por agricultores familiares que não participaram deste programa, ou seja, por não beneficiários $\left(E\left[Y_{i(0)} \mid D_{i}=1\right]\right)$. Nesse caso a equação anterior é substituída:

$$
\pi_{i}=e\left[Y_{i(1)} \mid D_{i}=1\right]-E\left[Y_{i(0)} \mid D_{i}=0\right]
$$

Essa equação permite a estimação do impacto do programa sobre o grupo de não beneficiários, mas com viés, já que existem diferenças entre $E\left[Y_{i(0)} \mid\right.$ $\left.D_{i}=1\right]$ e $E\left[Y_{i(0)} \mid D_{i}=0\right]$. O viés, para Heckman et al. (1997), compreende três componentes: exigência de diferenciação nas características observáveis; divergências na distribuição dessas características entre os dois grupos, e diferenças nos resultados, ainda que as características observáveis sejam controladas.

Para minimizar o viés, é introduzida a hipótese de o processo de seleção ser realizado mediante as características observáveis $\left(X_{i}\right)$ dos agricultores, correspondendo, algebricamente, à equação:

$$
E\left[Y_{i(0)}-Y_{i(1)}\right]=E\left[Y_{i(0)} \mid D_{i}=0, X\right]-E\left[Y_{i(1)} \mid D_{i}=1, X\right]
$$

Considerando que os agricultores com características observáveis idênticas possuem igual probabilidade de receber o benefício, os resultados $(Y)$ passam a ser independentes da participação no Programa. Nesse caso, $\left(Y_{i(0)}, Y_{i(1)} \perp\right.$ $\left.D_{i}\right)$; e a equação anterior é reescrita:

$$
E\left[Y_{i(0)}, Y_{i(1)} \mid D_{i}, X\right] \Rightarrow E\left[Y_{i(0)} \mid D_{i}=0, X\right]-E\left[Y_{i(1)} \mid D_{i}=1, X\right]
$$

As equações (8) e (9) estão apoiadas na hipótese da independência condicional, fundamental para o método do pareamento por escore de propensão.

A composição do grupo de não beneficiários, entretanto, com precedência nas características observadas, dificulta a aplicação do método do pareamento, já que, quanto mais características são utilizadas como base, maior será o número de observações necessário no grupo dos beneficiários para que se possa fazer o pareamento com o grupo de não beneficiários. 
Com vistas a solucionar essa dificuldade, recorre-se ao uso do método do Propensity Score Matching, ou escore de propensão, definido como a probabilidade de um indivíduo ser incluído em um programa. As variáveis que expressam as características observáveis $(X)$ são substituídas por probabilidades associadas a estas variáveis $P(X)$, ou seja:

$$
P(X)=\text { Probabilidade }(D=1 \mid X)
$$

A multidimensionalidade do pareamento pode ser resolvida por via do propensity score com a adoção de um escalar. Na equação anterior, $(X)$ pode ser substituído pelo escalar $P(X)$ :

$$
\begin{array}{r}
E\left[Y_{i(0)}-Y_{i(1)} \mid D_{i}=1, P(X)\right]=E\left[Y_{i(0)} \mid D_{i}=0, P(X)\right], \\
\text { então }\left(Y_{i(0)}, Y_{i(1)} \perp D \mid P(X)\right)
\end{array}
$$

O uso do propensity score, segundo Rosenbaum \& Rubin (1983), permite ajustar todo o viés entre os grupos de controle e de tratamento, desde que sejam assumidas as duas hipóteses descritas: a) Independência condicional - a seleção da amostra exige que a participação no programa independa dos resultados, sendo condicional nas covariáveis; b) Existência de suporte comum indivíduos do grupo de tratamento com características $(X)$ têm de apresentar correspondentes no grupo de controle.

Em relação ao escore de propensão, esse pressuposto (Heckman et al. 1999) estabelece que, para cada probabilidade estimada para os beneficiários, temse uma probabilidade semelhante para os não beneficiários. Sendo assim, $0<$ $P(X)<1$.

Asseguradas as existências dessas hipóteses, o impacto médio do Programa (average effect of treatment on treated - ATT) é obtido pela diferença entre o resultado médio do grupo de tratamento e do grupo de controle. Algebricamente, corresponde a:

$$
A T T=E\left\{E\left[Y_{i(1)} \mid D_{i}=1, p\left(x_{i}\right)\right]-E\left[Y_{i(0)} \mid D_{i}=0, p\left(x_{i}\right)\right] \mid D_{i}=1\right\}
$$

Complementando as estimativas, foram calculados os erros padrões do ATT através da técnica estatística denominada de Bootstrapping, que replica a amostragem com reposição dentro de cada subamostra para verificar a existência de impactos significativos do programa sobre a sustentabilidade agrícola. No presente estudo foram realizadas 50 replicações para cada estimativa de ATT.

\section{Resultados}

\subsection{O Índice de Sustentabilidade Agrícola}

Os agricultores familiares beneficiários do PRONAF apresentam Índice de Sustentabilidade Agrícola (ISA) de 0,58901(Tabela 2), o que os insere no nível médio de sustentabilidade agrícola. O Índice da Gestão Ambiental (IGA) de 0,39426 para os beneficiários, entretanto, é inferior ao obtido pelos não beneficiários, sendo este índice o que apresenta a menor contribuição para 
a formação do ISA (22,3\%). A participação percentual do Índice da Gestão Social (IGS) é mais do que o dobro do ISA $(46,07 \%)$, alcançando o valor de 0,81417, enquanto a participação do Índice da Gestão Econômica (IGE) é de $31,61 \%$, com o valor de 0,55861 .

O Índice de Sustentabilidade Agrícola (ISA) dos não beneficiários, no valor de 0,45779, é inferior ao observado para os beneficiários, o que os enquadra em baixo nível de sustentabilidade agrícola. Entrementes, diferentemente destes, os agricultores não beneficiários expressam Índice da Gestão Ambiental de 0,40479 , equivalente à participação de $29,48 \%$, no ISA, enquanto o Índice da Gestão Econômica (IGE) é de 0,37524 e o Índice da Gestão Social (IGS) é de 0,59333, equivalendo, respectivamente, as participações de $27,32 \%$ e $43,2 \%$ no ISA, percentuais esses inferiores aos dos beneficiários.

O baixo nível do Índice da Gestão Ambiental dos beneficiários e dos não beneficiários decorre, da não observância de boas práticas agrícolas, especialmente as de plantio, cujos indicadores são os que menos contribuíram, com apenas $10,57 \%$ e $10,77 \%$, respectivamente, para a formação do IGA dos respectivos grupos. Ao assim procederem, esses agricultores estão desdenhando do fato de que a continuidade da agricultura familiar depende, inexoravelmente, do uso sustentável dos recursos naturais, ou seja, da sustentabilidade agrícola para esta geração e a que poderia ser legada às futuras gerações.

O bom desempenho dos beneficiários, quanto ao Índice da Gestão Econômica, provém das significativas participações dos indicadores de Resiliência Econômica e Eficiência Financeira, cujas contribuições ao IGE são, respectivamente de $39,03 \%$ e $36,30 \%$, distinguindo-se dos não beneficiários que, nesses indicadores, apresentam participações percentuais de $33,52 \%$ e de $33,22 \%$ na formação do IGE.

Os agricultores beneficiários denotam elevado Índice da Gestão Social e isso os distingue dos não beneficiários, situados que estão em médio nível de sustentabilidade social. A contribuição do indicador de Confiança Institucional na composição do Índice da Gestão Social é a menos expressiva em ambos os grupos, com valores de $16,79 \%$ para os beneficiários e de $13,48 \%$ para os não beneficiários. No grupo dos beneficiários, no entanto, o indicador que mais contribuiu para o IGS foi o Sentimento de Pertencimento, com 22,52\%, enquanto para os não beneficiários o indicador de maior participação percentual no IGS, com $25,75 \%$ é o de Reforço de Laços e Valores.

\subsection{Estimação do modelo logit}

As variáveis passíveis de influenciar o acesso ao PRONAF (Tabela 1) expressam qualidades e atributos dos agricultores familiares, de seus domicílios e da propriedade rural percebidos e coletados quando da aplicação das entrevistas semiestruturadas.

Além das variáveis explicativas, o modelo logit exige a inclusão de variáveis independentes ou preditoras (Apêndice A) que podem influenciar a participação de agricultores familiares no PRONAF.

Para analisar a influência dessas características sobre o processo de seleção ao PRONAF é aplicado o modelo de regressão com variável dependente binária, ou seja, o modelo logit.

modelo (cujos resultados estão apresentados na Tabela 3) mostra que, das 12 variáveis que o compõem, seis são significativas estatisticamente no nível de $1 \%$ e de $5 \%$ e, destas, três - escolaridade, água disponível na pro- 
Tabela 2: Contribuição dos indicadores e Composição do Índice de Sustentabilidade Agrícola (ISA) de beneficiários e não beneficiários do PRONAF, na região do Vale do Médio Curu

\begin{tabular}{|c|c|c|c|c|c|c|}
\hline \multirow[b]{2}{*}{ Índices e Indicadores } & \multicolumn{3}{|c|}{ Beneficiários } & \multicolumn{3}{|c|}{ Não Beneficiários } \\
\hline & $\begin{array}{c}\text { Valor } \\
\text { Absoluto }\end{array}$ & $\begin{array}{c}\text { Part. }(\%) \\
\text { Índices }\end{array}$ & $\begin{array}{c}\text { Part. }(\%) \\
\text { no ISA }\end{array}$ & $\begin{array}{c}\text { Valor } \\
\text { Absoluto }\end{array}$ & $\begin{array}{c}\text { Part. }(\%) \\
\text { Índices }\end{array}$ & $\begin{array}{c}\text { Part. (\%) } \\
\text { no ISA }\end{array}$ \\
\hline Índice da Gestão Ambiental & 0,39426 & 100,00 & 22,32 & 0,40479 & 100,00 & 29,48 \\
\hline Práticas de preparo do solo & 0,14000 & 35,51 & & 0,14688 & 36,29 & \\
\hline . Práticas de plantio & 0,04167 & 10,57 & & 0,04360 & 10,77 & \\
\hline Práticas de pós-plantio & 0,09833 & 24,94 & & 0,09920 & 24,51 & \\
\hline . Práticas de combate às pragas & 0,07167 & 18,18 & & 0,08400 & 20,75 & \\
\hline . Serviços de assistência técnica & 0,04259 & 10,80 & & 0,03111 & 7,68 & \\
\hline Índice da Gestão Econômica & 0,55861 & 100,00 & 31,61 & 0,37524 & 100,00 & 27,32 \\
\hline . Organização da propriedade & 0,13778 & 24,67 & & 0,12480 & 33,26 & \\
\hline Eficiência financeira & 0,20278 & 36,30 & & 0,12466 & 33,22 & \\
\hline . Resiliência econômica & 0,21805 & 39,03 & & 0,12578 & 33,52 & \\
\hline Índice da Gestão Social & 0,81417 & 100,00 & 46,07 & 0,59333 & 100,00 & 43,20 \\
\hline . Confiança institucional & 0,13667 & 16,79 & & 0,08000 & 13,48 & \\
\hline . Organização de mercados & 0,17833 & 21,86 & & 0,12760 & 21,51 & \\
\hline Sentimento de pertencimento & 0,18333 & 22,52 & & 0,13813 & 23,28 & \\
\hline . Reforço de laços e valores & 0,17667 & 21,74 & & 0,15280 & 25,75 & \\
\hline . Part. Social em defesa interesses & 0,13917 & 17,09 & & 0,09480 & 15,98 & \\
\hline Índice Sustentabilidade Agrícola & 0,58901 & & 100,00 & 0,45779 & & 100,00 \\
\hline
\end{tabular}

Fonte: Dados da Pesquisa 
priedade e condições de moradia - mostram coeficientes com sinal positivo, correlacionando-se diretamente com a participação no PRONAF. Dessa forma, o agricultor familiar com maior escolaridade, com disponibilidade de água na propriedade, residente em casa própria e casa de alvenaria, apresenta maior propensão de se tornar beneficiário do Programa.

As variáveis tempo de trabalho na propriedade, número de cômodos e área colhida, registram coeficientes com sinais negativos, denotando relação inversa entre estas e a probabilidade de participar do PRONAF. Assim, o agricultor familiar que dispõe de maior área colhida e mais tempo de trabalho na propriedade apresenta menor perspectiva de integrar o PRONAF, confirmando que o foco do Programa é o pequeno agricultor familiar, independentemente, da tradição na agricultura.

Tabela 3: Modelo de regressão logit para a variável beneficiário do PRONAF na região do Vale do Médio Curu, no Ceará

\begin{tabular}{l|c|c|c|c}
\hline Variável & Coeficiente & Erro Padrão & $\mathbf{z}$ & $|P>| z \mid$ \\
\hline Idade & 0,0250727 & 0,014705 & 1,710 & 0,088 \\
Estado Civil & $-0,1944873$ & 0,230630 & $-0,840$ & 0,399 \\
Escolaridade & 2,3630940 & 0,537493 & 4,400 & 0,000 \\
Sabe ler e escrever & $-1,1163150$ & 0,810462 & $-1,380$ & 0,168 \\
Tempo trabalho na propriedade & $-0,3904292$ & 0,187700 & $-2,080$ & 0,038 \\
Água disponível na propriedade & 0,7543273 & 0,347808 & 2,170 & 0,030 \\
Condições de moradia & 0,8790942 & 0,411866 & 2,130 & 0,033 \\
Tipo de construção moradia & 0,4900089 & 0,571526 & 0,860 & 0,391 \\
Número de cômodos & $-0,2914720$ & 0,143051 & $-2,040$ & 0,042 \\
Área Colhida & $-3,553717$ & 1,74487 & $-2,040$ & 0,042 \\
Número Homem-Dia Familiar & 0,3071627 & 0,157865 & 1,950 & 0,052 \\
Índice prop. à sust.agrícola (isa2) & $-0,0043139$ & 0,008301 & $-1,070$ & 0,284 \\
\hline
\end{tabular}

Fonte: Dados da pesquisa

As variáveis idade e número de homens-dia familiar são estatisticamente significantes em nível de $10 \%$. Entretanto, são menos relevantes à inserção do não beneficiário no PRONAF do que a escolaridade e as condições de moradia.

Essas variáveis ganham proeminência, uma vez que o nível maior de escolaridade oferece mais facilidades à adoção de tecnologias, além de ampliar a capacidade de tomada de decisões e, consequentemente, melhorar a gestão da propriedade rural. Em relação às condições de moradia, a posse da moradia ou a "casa própria" é motivo de orgulho para o agricultor. Ademais, ao integrar o patrimônio pessoal, a casa própria simboliza o sucesso profissional e o progresso financeiro, obtido ao longo de toda uma vida.

As variáveis estado civil, sabe ler e escrever, tipo de construção da moradia e indice de propensão à sustentabilidade agrícola (isa2) não representam qualquer influência em relação à probabilidade de o não beneficiário participar do PRONAF.

\subsection{O ajuste do modelo logit}

O modelo logit constante da Tabela 4 foi confirmado em função da qualidade de ajustamento das variáveis segundo os valores dos critérios: função de ve- 
rossimilhança (log likelihood); Informação Akaike (AIC), Informação de Bayesiano (BIC), pseudo $R^{2}$ e o percentual de casos corretamente classificados.

Tabela 4: Testes de qualidade de ajuste da regressão logit para comparação de beneficiários e não beneficiários do PRONAF na região do Vale do Médio Curu no Ceará

\begin{tabular}{l|c}
\hline Critério & Coeficiente \\
\hline Função de verossimilhança (log likelihood) & $-83,268307$ \\
Valor do critério AIC & 1,041 \\
Valor do critério BIC & $-731,365$ \\
Valor do pseudo R 2 & 0,2827 \\
Percentagem de casos corretamente classificados & 79,46 \\
\hline Fonte:
\end{tabular}

O valor do pseudo $R^{2}$ de 0,2827 , embora moderado, é aceitável, considerandose que mais de $79 \%$ das variações na inclusão de beneficiários do PRONAF podem ser explicadas pelas variáveis explicativas inseridas no modelo. Esses resultados, juntamente com os demais critérios, atestam a boa qualidade de ajuste do modelo selecionado, assegurando que este é crível e adequado para explicar a inclusão de agricultores familiares como beneficiários do PRONAF.

\subsection{Cálculo do Odds Ratio}

Os valores dos odds ratio expressam a variação do logaritmo natural da relação das probabilidades de sucesso ou insucesso do não beneficiário se tornar beneficiário do PRONAF.

Para a variável idade, segundo a Tabela 5 , o valor do odds ratio é maior do que a unidade $(1,025)$, sinalizando que o não beneficiário com maior idade, eleva em 2,5\% suas chances de participar do Programa.

A variável escolaridade destaca-se na comparação entre beneficiários e não beneficiários do PRONAF segundo o valor do odds ratio, indicando que o nível de escolaridade mais elevado aumenta bastante a propensão de um agricultor familiar não beneficiário se tornar beneficiário do Programa.

Para os não beneficiários, o maior tempo de trabalho na propriedade (odds ratio $=0,6767)$ representa uma probabilidade de 32,3\% de não serem inclúídos no PRONAF.

Em relação ao tipo de construção da moradia (odds ratio $=1,632331$ ), verificase que o agricultor que possui casa de alvenaria aumenta em $63,23 \%$ sua probabilidade de integrar o Programa.

O maior número de cômodos na moradia do não beneficiário (odds ratio $=0,747)$ reduz em $25,3 \%$ suas chances de vir a se tornar beneficiário do Programa. Isso pode ser entendido que o agricultor com maior número de cômodos, ou seja, com residência maior, tem menor propensão de integrar o PRONAF.

\section{Avaliação de impactos do PRONAF}

A avaliação das estimativas dos impactos do PRONAF sobre a sustentabilidade agrícola assenta-se no critério de eficácia, ou seja, o Programa é real- 
Tabela 5: Valores do odds ratio para o modelo de regressão logit a fim de comparar beneficiários e não beneficiários do PRONAF na região do Vale do Médio Curu no Ceará

\begin{tabular}{l|c|c|c|c}
\hline Variável & Odds Ratio & Erro Padrão & $\mathbf{z}$ & $|P>| z \mid$ \\
\hline Idade & 1,025390 & 0,150783 & 1,710 & 0,088 \\
Estado Civil & 0,823257 & 0,189868 & $-0,840$ & 0,399 \\
Escolaridade & 10,623770 & 5,710204 & 4,400 & 0,000 \\
Sabe ler e escrever & 0,327484 & 0,265414 & $-1,380$ & 0,168 \\
Tempo de trabalho na propriedade & 0,676766 & 0,127029 & $-2,080$ & 0,038 \\
Água disponível na propriedade & 2,126181 & 0,739503 & 2,170 & 0,030 \\
Condições de moradia & 2,408717 & 0,992069 & 2,130 & 0,033 \\
Típo de construção da moradia & 1,632331 & 0,932919 & 2,130 & 0,033 \\
Número de cômodos & 0,747163 & 0,106882 & $-2,040$ & 0,042 \\
Área Colhida & 0,028618 & 0,499348 & $-2,040$ & 0,042 \\
Número Homem-Dia Familiar & 1,359562 & 0,214628 & 1,950 & 0,052 \\
Índice prop. à sust. agrícola (isa2) & 0,995695 & 0,008265 & $-0,520$ & 0,603 \\
\hline
\end{tabular}

Fonte: Dados da pesquisa.

mente eficaz se é capaz de influenciar positivamente e de maneira conjunta todas as variáveis.

Nesse contexto, a avaliação das estimativas dos efeitos do PRONAF (Tabela 6) traz os resultados decorrentes da comparação dos índices e indicadores sobre a sustentabilidade agrícola de beneficiários e não beneficiários.

Para determinar essas estimativas de impactos, procedeu-se ao cálculo do ATT (average effect of treatment on treated) para todas as variáveis resposta considerando-se o método de pareamento do vizinho mais próximo (nearest Neighbor Matching - NNM = 5).

Os valores positivos do ATT indicam que as estimativas de impactos são favoráveis ao Programa. Entretanto, a validação desses valores é realizada por intermédio do valor da estatística $t$ de Student.

Na comparação entre beneficiários e não beneficiários do PRONAF, os valores dos ATT e a estatística " $t$ " (Tabela 6) demonstram a existência de estimativas de impactos positivos do PRONAF para o Índice de Sustentabilidade Agrícola em curto prazo, com proeminência do Índice da Gestão Social, seguido do Índice da Gestão Econômica e, em destaque especial, a Receita Agrícola Anual.

Para o Índice da Gestão Ambiental, todavia, observa-se que as estimativas dos valores do IGA são muito semelhantes entre os dois grupos (Tabela 6), mas percebe-se pequena desvantagem dos beneficiários para cinco dos seis indicadores dessa dimensão (práticas de preparo do solo, de pós-plantio, de combate às pragas e serviços de assistência técnica), o que denota um sério problema para a sustentabilidade ambiental desses agricultores familiares. No indicador de práticas de preparo do solo, $26,7 \%$ e $36,7 \%$, respectivamente, dos beneficiários fazem desmatamento e queimadas, enquanto $11,3 \%$ e $23,6 \%$ dos não beneficiários empregam essas práticas insustentáveis (Passos 2014). No indicador de práticas de combate às pragas, $90 \%$ e $91,7 \%$ dos beneficiários e $86,4 \%$ e $85,6 \%$ dos não beneficiários, usam produtos químicos e aplicam defensivos, respectivamente. As estimativas favoráveis de impactos para o indicador práticas de plantio decorrem da adoção de práticas sustentáveis, como o plantio direto, usado por $6,7 \%$ dos beneficiários, rotação de culturas, implementada 
por $3,3 \%$ destes, e usos de esterco e fertilizante, admitidos, respectivamente, por $36,7 \%$ e $51,7 \%$ dos beneficiários. No indicador de acesso aos serviços de assistência técnica, constata-se que, em relação à frequência, apenas $8,3 \%$ dos beneficiários recebem esses serviços mensalmente, enquanto para $83,4 \%$ desses a periocidade dos serviços ultrapassa os dois meses. Entre os não beneficiários, 16,7\% recebem assistência técnica mensalmente, todavia, para 63,9\% desses agricultores, os serviços são prestados com frequência superior a dois meses. A maior eficiência nesses serviços pode melhorar a produção agrícola, e a conquista de novos conhecimentos e tecnologias pode motivar os agricultores familiares à adoção de práticas agrícolas sustentáveis e economicamente mais rentáveis, elevando a receita agrícola dos agricultores.

Quanto ao Índice da Gestão Econômica, é notorio que o PRONAF mostra indicativos de impactos favoráveis para os beneficiários (Tabela 6), o mesmo ocorrendo para todos os três indicadores deste índice. Destaca-se, no entanto, o de Eficiência Financeira, com estimativas de impactos mais significativos, considerando-se que $71,7 \%$ dos beneficiários auferem renda agrícola por hectare inferior a $\mathrm{R} \$ 4.000,00$, enquanto somente $28,0 \%$ dos não beneficiários chegam a esse nível. A renda agrícola por hectare, para a maioria dos não beneficiários $(64,0 \%)$, é inferior a $\mathrm{R} \$ 2.000,00$.

Ainda compondo o Índice da Gestão Econômica, verifica-se que existem indicativos de impactos favoráveis do Programa em relação ao indicador de Resiliência Econômica dos agricultores beneficiários. Esse indicador procura identificar quão preparado está o agricultor familiar para enfrentar as adversidades climáticas (secas), frequentes no Ceará, bem como as perdas biológicas decorrentes de doenças e ataques de insetos. Surpreendentemente, em caso de seca, a predisposição de abandonar a agricultura é a opção menos acolhida pelos agricultores: $6,7 \%$ para os beneficiários e de 7,2\% para os não beneficiários. Essa opção revela que o agricultor beneficiário e o não beneficiário, de modo semelhante, estão dispostos a enfrentar as vicissitudes, que são, de certa maneira, recorrentes na atividade agrícola. Em relação à Garantia contra Adversidades Climáticas, 65\% dos beneficiários e 52\% dos não beneficiários afirmaram que recorreriam ao Seguro Safra para amenizar os prejuízos financeiros. Como proteção contra eventuais dificuldades, 61,7\% dos beneficiários e, apenas, 13,6\% dos não beneficiários admitem recorrer à diversificação da produção. Além de reduzir os riscos decorrentes da incidência de fatores biológicos (pragas e doenças), a diversificação ainda promove a elevação da receita agrícola anual, já que permite melhor distribuição da receita agrícola entre os variados produtos, atenuando os possíveis declínios de preços. Ademais, a diversificação da produção favorece a integração ao mercado do agricultor familiar. O despreparo do agricultor familiar para enfrentar os riscos da atividade agrícola é constatado ao se observar que a maioria dos não beneficiários $(64,8 \%)$ e, somente, $6,7 \%$ dos beneficiários asseveram não possuir nenhuma garantia contra as vicissitudes da atividade.

Na composição do Índice da Gestão Social, os agricultores beneficiários apresentam supremacia em relação aos não beneficiários em três dos cinco indicadores: sentimento de pertencimento, reforço de laços e valores e confiança institucional.

As indicações dos maiores impactos positivos do PRONAF concentram-se no IGS dos beneficiários, com predominância dos valores apresentados pelo indicador de sentimento de pertencimento, no qual 90\% destes asseveram confiar na ajuda dos amigos em caso de dificuldades, 95\% afirmam que costumam 
Tabela 6: Estimativas de Impactos do PRONAF através do propensity score matching para dados pareados de beneficiários e não beneficiários na mesorregião do Vale do Médio Curu no Ceará

\begin{tabular}{|c|c|c|c|c|c|}
\hline \multirow{2}{*}{ Variável } & \multicolumn{2}{|c|}{ Valores Médios } & \multirow{2}{*}{$\begin{array}{c}\text { ATT } \\
\text { Diferença }\end{array}$} & \multirow{2}{*}{$\begin{array}{c}\text { Erro } \\
\text { Padrão }\end{array}$} & \multirow{2}{*}{$t$} \\
\hline & Beneficiários & Não Beneficiários & & & \\
\hline Índice de Gestão Ambiental & 0,38846 & 0,42575 & $-0,03730$ & 0,02961 & $-1,26$ \\
\hline Práticas de Preparo de Solo & 0,13895 & 0,14540 & $-0,00646$ & 0,00972 & $-0,66$ \\
\hline Práticas de Plantio & 0,42105 & 0,40000 & 0,00211 & 0,00933 & 0,23 \\
\hline Práticas de Pós-Plantio & 0,09825 & 0,09930 & $-0,00105$ & 0,00362 & $-0,29$ \\
\hline Práticas Combate às Pragas & 0,07193 & 0,09825 & $-0,02632$ & 0,22463 & $-1,17$ \\
\hline Serv. Assistência Técnica & 0,03723 & 0,04281 & $-0,00558$ & 0,01451 & $-0,38$ \\
\hline Índice de Gestão Econômica & 0,55556 & 0,35825 & 0,19731 & 0,02812 & 7,02 \\
\hline Organização da Propriedade & 0,13450 & 0,11906 & 0,01544 & 0,01485 & 1,04 \\
\hline Eficiência Financeira & 0,20175 & 0,11053 & 0,91228 & 0,01297 & 7,03 \\
\hline Resiliência Econômica & 0,21930 & 0,12865 & 0,09064 & 0,01921 & 4,72 \\
\hline Índice de Gestão Social & 0,81725 & 0,57275 & 0,24450 & 0,03217 & 7,60 \\
\hline Confiança Institucional & 0,13684 & 0,06573 & 0,07111 & 0,01356 & 5,25 \\
\hline Organização de Mercados & 0,17719 & 0,12386 & 0,05333 & 0,00640 & 8,33 \\
\hline Sentimento de Pertencimento & 0,18480 & 0,14947 & 0,03532 & 0,01278 & 2,76 \\
\hline Reforço de Laços e Valores & 0,17719 & 0,14842 & 0,02877 & 0,11584 & 2,48 \\
\hline Part. Social Defesa Interesses & 0,14123 & 0,08526 & 0,55965 & 0,01810 & 3,09 \\
\hline Índice de Sustentab. Agrícola & 0,58709 & 0,45225 & 0,13484 & 0,02002 & 6,73 \\
\hline Receita Agrícola Anual & 5468,35090 & 1847,94386 & 3620,5912 & 895,90288 & 4,04 \\
\hline
\end{tabular}

Fonte: Dados da pesquisa. 
ajudar os amigos em caso de dificuldades e 90\% participam de comemorações de datas festivas. Entre os não beneficiários, a participação percentual nesses indicadores é de $60,8 \%, 88,0 \%$ e $58,4 \%$, respectivamente.

As estimativas de impacto do Programa na Receita Agrícola Anual são mais favoráveis aos beneficiários e podem ser explicadas considerando-se que a renda agrícola anual para $71,7 \%$ dos beneficiários é de até $\mathrm{R} \$ 3.000,00$, para $21,7 \%$ destes é de até $R \$ 6.000,00$ e para 6,6\% ultrapassa $R \$ 6.000,00$ (Passos 2014). Embora modestos, os resultados atestam a viabilidade econômica, em curto prazo da produção agrícola dos agricultores familiares beneficiários. Entretanto, no longo prazo, a sustentabilidade econômica pode não ser passível de alcançar, dadas as incertezas de manter ou ampliar uma produção sustentável em longo prazo sem necessidade de transferir a posse da propriedade para terceiros.

\subsection{Teste de Hipótese para as estimativas do ATT com o método Bootstrapping}

O método Bootstrapping tem por objetivo validar os valores das estimativas de ATT (Tabela 7), identificando os impactos efetivamente significativos sobre a sustentabilidade agrícola de beneficiários e não beneficiários do PRONAF.

Tabela 7: Resultados do Teste de Hipótese para a estimativa ATT, usando Bootstrapping, para beneficiários e não beneficiários PRONAF na mesorregião do Médio do Vale do Curu, no Ceará

\begin{tabular}{l|c|c|c|c}
\hline Variável & $\begin{array}{c}\text { Coeficiente } \\
\text { observado }\end{array}$ & $\begin{array}{c}\text { Erro Padrão } \\
\text { Bootstrapping }\end{array}$ & $\mathbf{z}$ & $P>|z|$ \\
\hline Índice de Gestão Ambiental & $-0,0655404$ & 0,0425502 & $-1,54$ & 0,123 \\
Índice de Gestão Econômica & 0,1375926 & 0,051188900 & 2,69 & 0,007 \\
Índice de Gestão Social & 0,2061111 & 0,052705400 & 3,91 & 0,000 \\
Índice Sustentabilidade Agrícola & 0,0927222 & 0,045142600 & 2,05 & 0,040 \\
Receita Agrícola Anual & 4046,592 & 790,5618 & 5,120 & 0,000 \\
\hline
\end{tabular}

Fonte: Dados da pesquisa

Os dados constantes da Tabela 7 permitem observar que a estimativa de ATT para o Índice da Gestão Ambiental não é validada pelo Teste de Bootstrapping, sinalizando que o PRONAF não se mostrou capaz de incentivar a melhoria de práticas agrícolas sustentáveis, essenciais para assegurar a sustentabilidade ambiental dos agricultores familiares, que dependem de uma agricultura sustentável para viabilizar a continuidade e dinamização das comunidades rurais. Ademais, a insustentabilidade ambiental compromete, seriamente, a sustentabilidade agrícola desses agricultores em longo prazo e, consequentemente, a dinamização da economia dos territórios rurais.

O PRONAF, segundo os resultados do teste, apresenta, todavia, impactos favoráveis para o Índice da Gestão Econômica, Índice da Gestão Social, Receita Agrícola Anual e para o Índice de Sustentabilidade Agrícola.

Em relação ao Índice da Gestão Econômica, o resultado legitima a estimativa do ATT, demonstrando que a agricultura familiar apresenta sustentabilidade econômica. Entretanto, a adoção de práticas mais sustentáveis contribuiria para elevar a produtividade e, consequentemente, a eficiência financeira dos sistemas agrícolas familiares, assegurando a continuidade do segmento e maior bem-estar aos agricultores familiares . 
O PRONAF tem impacto positivo no Índice da Gestão Social, confirmando os resultados indicativos do ATT, ou seja, os agricultores familiares são altamente favorecidos quanto à sustentabilidade social, demonstrando que o Programa contribui para a interação e a coesão social de seus beneficiários.

Finalmente, o Teste de Bootstrapping ratifica a estimativa favorável do ATT para o impacto do Programa sobre a Renda Agrícola Anual, confirmando o impacto positivo do Programa para a viabilidade econômica da agricultura familiar, ainda que modestamente, conforme descrição procedida no item anterior, mas consistente com as precárias práticas de produção e recebimento de assistência técnica.

\section{Considerações Finais}

Neste estudo, investigou-se o impacto do PRONAF sobre a sustentabilidade agrícola de agricultores familiares na microrregião do Vale do Médio Curu, no Estado do Ceará. Para tanto, foram utilizados dados de origem primária, resultantes da aplicação de questionários semiestruturados junto aos agricultores familiares. O pressuposto assumido foi o de que os agricultores familiares detinham sustentabilidade agrícola.

A metodologia aplicada na avaliação de impacto foi a do Propensity Score Matching, amplamente utilizada e reconhecida na literatura de avaliação, pela capacidade de medir impactos reais atribuíveis ao Programa.

$\mathrm{Na}$ análise das características pessoais e socioeconômicas dos agricultores que podem influenciar o acesso ao PRONAF, destacam-se a escolaridade, a disponibilidade de moradia própria e de água na propriedade. Entretanto, quanto maiores a área colhida e a experiência do agricultor, menor é a probabilidade de ingresso no Programa. Por outro lado, o tipo de construção da moradia, o estado civil e se sabe ler e escrever não exercem qualquer vantagem na seleção como beneficiário.

Os resultados do propensity score matching mostram que o PRONAF não apresenta impactos positivos sobre a gestão ambiental dos agricultores beneficiários, contrariando a diretriz, inserida no Decreto 6.882/09, de reformulação do Programa, que prevê " melhor uso dos recursos naturais". Para as regiões mais pobres e com limitadas fontes de emprego e renda, o uso de práticas agrícolas mais sustentáveis e, consequentemente, a sustentabilidade agrícola, são questões de sobrevivência e continuidade do segmento da agricultura familiar.

Não obstante esse resultado, o PRONAF registra impactos positivos na sustentabilidade agrícola em curto prazo dos agricultores familiares, o mesmo ocorrendo em relação aos índices da gestão econômica e social da propriedade e à renda agrícola anual. A sustentabilidade agrícola em longo prazo, todavia, requer uma harmoniosa combinação dessas dimensões que, interligadas, constituem a base de uma agricultura sustentável. Como essas dimensões estão interconectadas, a melhoria da receita agrícola (gestão econômica), por si, não tem sentido se não vier acompanhada de uma melhoria nos desempenhos das gestões ambientais e sociais. De igual modo, a adoção de práticas agrícolas mais sustentáveis, sem a melhoria da renda agrícola e das questões sociais e culturais, não é capaz de manter a viabilidade da agricultura familiar.

Dada a relevância do segmento da agricultura familiar, sugere-se a efetivação de estudos mais abrangentes, objetivando consolidar regionalmente os 
resultados aqui apresentados, de maneira a reorientar essa política pública, que é o elo de fortalecimento desse segmento.

\section{Referências Bibliográficas}

Allen, P., Van Dusen, D., Lundy, J. \& Gliessman, S. (1991), 'Expanding the definition of sustainable agriculture', Center for Agroecology and Sustainable Agriculture .

Aquino, J. R. \& Schneider, S. (2010), '12 anos da Política de crédito do PRONAF no Brasil (1996-2008): uma reflexão crítica', in Congresso Latinoamericno de Sociologia Rural, Porto de Galinhas (PE), p. 8.

Binder, C. R., Schmid, A. \& Steinberger, J. (2012), 'Sustainability solution space of the Swiss milk value added chain', Ecological Economics 83, 210-220.

Brasil (2010), Plano Territorial de Desenvolvimento Rural Sustentável: Território Cidadania Vales do Curu e Aracatiaçu, - MDA/SDT/AMUV, Fortaleza: Instituto Agropolos do Ceará. Ministério do Desenvolvimento Agrário (MDA).

Brasil (2017), Novo Plano Safra da agricultura familiar 2017/2018. Brasília: Ministério do Desenvolvimento Agrário (MDA).

URL: 'Disponivel em: <http://www.mda.gov.br/sitemda/noticias/Acesso em 12 de junho de 2017

Chaddad, F. R., Jank, M. S. \& Nakahodo, S. N. (2006), 'Repensando as políticas agrícola e agrária do Brasil', Revista Digesto Econômico .

Cochran, W. (1977), Sampling Tecniques, 3rd ed, Wiley.

Damasceno, N. P., Khan, A. S. \& Lima, P. V. S. (2011), 'O impacto do Pronaf sobre a sustentabilidade da agricultura familiar, geração de emprego e renda no Estado do Ceará', Revista de Economia e Sociologia Rural 49(1), 129-156.

De Koeijer, T. J., Wossink, G. A. A., Van Ittersum, M. K., Struik, P. C. \& Renkema, J. A. (1999), 'A conceptual model for analyzing input-output coefficients in arable farming systems: From diagnosis towards design', Agricultural Systems 61, pp. 33-44.

Del Grossi, M. (2011), Agricultura familiar no Censo Agropecuário 2006, Congresso da Sociedade Brasileira de Economia, Administração e Sociologia Rural, Belo Horizonte: SOBER.

Dumanski, J. (1997), 'Criteria and indicators for land quality and sustainable land management'.

Dumanski, J., Terry, E., Byerlee, D. \& Pieri, C. (1998), 'Performance indicators for sustainable agriculture'. Washington (DC): World Bank. (Discussion Note).

Feijó, R. (2001), The impact of a family farming credit programme on the rural economy of Brazil, in 'Anais do Congresso de Economia ANPEC 29'.

Frater, P. \& Franks, J. (2013), 'Measuring agricultural sustainability at the farm-level: A pragmatic approach', International Journal of Agricultural Management 2(4), 207-225. 
Gazolla, M. \& Schneider, S. (2013), 'Qual fortalecimento da agricultura familiar? Uma análise do Pronaf crédito de custeio e investimento no Rio Grande do Sul', Revista de Economia e Sociologia Rural 51, 45-68.

Gil, A. C. (2008), Métodos e Técnicas de Pesquisa Social, 6. ed., São Paulo: Atlas.

Gomes, E. G., Mello, J. C. C. B. S. \& Mangabeira, J. A. C. (2009), 'Estudo da sustentabilidade agrícola em município amazônico com análise envoltória de dados', Pesquisa Operacional 29(1), 23-45.

Goodland, R. (1995), 'The concept of environmental sustainability', Annual Review of Ecology and Systematics 26, 1-24.

Grisa, C. (2010), 'As políticas públicas para a agricultura familiar no Brasil: um ensaio a partir da abordagem cognitiva', Desenvolvimento em Debate 1(2), 83-109.

Grisa, C., Wesz Junior, V. J. \& Buchweitz, V. D. (2014), 'Revisitando o Pronaf: velhos questionamentos, novas interpretações', Revista de Economia e Sociologia Rural 52(02), 323-346.

Guanziroli, C. E. (2007), 'PRONAF dez anos depois: resultados e perspectivas para o desenvolvimento rural', Revista de Economia e Sociologia Rural 45(2), 301-328.

Gómez-Limón, J. \& Sanchez-Fernandez, G. (2010), 'Empirical evaluation of agricultural sustainability using composite indicators', Ecological Economics 69, 1062-1075.

Hansen, J. W. \& Jones, J. W. (1996), 'A systems framework for characterizing farm sustainability', Agricultural Systems . Essex, England, GB, 51, 185-201.

Heckman, J., Ichimura, H. \& Todd, P. (1997), 'Matching as an econometric evaluation estimator: evidence from evaluating a job training program', $R e-$ view of Economic Studies 64(4), 605-654.

Heckman, J., Lalonde, R. \& Smith, J. (1999), The economics and econometrics of active labor market programs, in Ashenfelter, O. C. \& Card, D., eds, Handbook of Labor Economics, vol. 3, part A, ch. 31.

Häni, F., Braga, F., Stämpfli, A Keller, T., Fischer, M. \& Porsche, H. (2003), 'Rise, a tool for holistic sustainability assessment at the farm level', International Food and Agribusiness Management Review 6(4), 78-90.

IPEA (2013), Caracterização do público potencial do PRONAF “B” na região Nordeste e no Estado de Minas Gerais. Uma análise baseada nos dados do Censo Agropecuário 2006, Technical report. Brasília: IPEA. (Relatório de pesquisa).

Lopes, S. B. (2001), Arranjos institucionais e a sustentabilidade de sistemas agroflorestais: uma proposição metodológica, PhD thesis. Porto Alegre: UFRGS, 182 p. (Dissertação de Mestrado em Desenvolvimento Rural).

Lourenzani, W. L. (2006), 'Capacitação gerencial de agricultores familiares: uma proposta metodológica de extensão rural’, Organizações Rurais E Agroindustriais 8(3), 313-322. 
Magalhães, A. M., Silveira Neto, R., Dias, F. M. \& Barros, A. R. (2006), 'A experiência recente do PRONAF em Pernambuco: uma análise por meio de propensity score', Economia Aplicada 10(1), 57-74.

Mattei, L. (2005), 'Impactos do PRONAF: análise de indicadores', Núcleo de Estudos Agrários e Desenvolvimento Rural - NEAD .

Moreira, V. S., Silveira, S. F. R. \& Motter, K. Z. (2014), 'Avaliação do PRONAF B sobrea satisfação de agricultores familiares em municípios de Minas Gerais', Estudos, Sociedade e Agricultura 22(2), 432-456.

Nações Unidas (2007), 'Coesão Social. Inclusão e sentido de pertencer na América Latina e no Caribe'. Santiago do Chile: CEPAL.

Nações Unidas (2010), 'Social cohesion in Latin America: concepts, frames of reference and indicators'. Santiago de Chile: CEPAL.

Neder, H. D. \& Buainain, A. M. (2012), Impactos do PRONAF sobre indicadores sociais da agropecuária no Brasil no período de 2000 a 2010, in 'Congresso da SOBER 50'.

Norman, D. W. \& Dixon, J. (1995), 'Sustainable dry land cropping in relation to soil productivity'. Rome: FAO. (FAO Soils Bulletin 72).

Passos, A. T. B. (2014), O impacto do PRONAF sustentável sobre a sustentabilidade agrícola da agricultura familiar: o caso da microrregião do Vale do Médio Curu no Estado do Ceará, PhD thesis. Fortaleza: UFC. (Tese de Doutorado em Desenvolvimento e Meio Ambiente).

PNUD, (2013). Índice de Desenvolvimento Humano Municipal no Brasil, Brasília: IPEA, FJP. Programa das Nações Unidas para o Desenvolvimento.

Pretty, J. (2006), 'Agroecological approaches to agricultural development'. Washington (DC): World Bank.

Reidsma, P., Bakker, M. M., Kanellopoulos, A., Alam, S. J., Kros, J. \& Vries, W. (2015), 'Sustainable agricultural development in a rural area in the Netherlands? Assessing impacts of climate and socioeconomic change at farm and landscape level', Agricultural Systems 141, 160-173.

Rigby, D., Woodhouse, P., Young, T. \& Burton, M. (2001), 'Constructing a farm level indicator of sustainable agricultural practice', Ecological Economics 39, 463-478.

Rinne, J., Lyytimäki, J. \& Kautto, P. (2013), 'From sustainability to well-being: lessons learned from the use of sustainable development indicators at national and EU level', Ecological Indicators 35, 35-42.

Rosenbaum, P. R. \& Rubin, D. (1983), 'The central role of the propensity score in observational studies for causal effects', Biometrika 70(1), 41-55.

Roy, A. D. (1951), 'Some thoughts of the distribution of earning', Oxford Economic Papers 3(2), 135-146.

Rubin, D. (1974), 'Estimating causal effects to treatments in radomized and nonrandomized studies', Journal of Educational Psycology 5(66), 688-701. 
Ryan, M., Buckley, C., Dillon, E. J., Donnellan, T., Hanrahan, K., Hennessy, T. \& Moran, B. (2014), 'The development of farm-level sustainability indicators for Ireland using the Teagase National Farm Survey'. in 88th Annual Conference of the Agricultural Economics Society, Paris: Agro Paris Tech.

Sands, G. R. \& Podmore, T. H. (2000), 'A generalized environmental sustainability index for agricultural systems', Agriculture, Ecosystems and Environment 79, 29-41.

Santos, G. J. \& Marion, J. C. (1996), Administração de custos na agropecuária, 2. ed, São Paulo: Atlas.

Schaller, N. (1993), 'Sustainable agriculture and the environment. The concept of agricultural sustainability', Agriculture, Ecosystems and Environment 46, 89-97.

Schneider, S., Cazella, A. \& Mattei, L. (2004), 'Histórico, caracterização e dinâmica recente do Pronaf-Programa Nacional de Fortalecimento da Agricultura Familiar'. In: Schneider, S., Silva, M. K. \& Marques, P. E. M., eds, Políticas públicas e participação social no Brasil rural, Porto Alegre: UFRGS, pp. 21-49.

Singh, R. K., Murty, H. R., Gupta, S. K. \& Dikshit, A. K. (2012), 'An overview of sustainability assessment methodologies', Ecological Indicators 15(1), 281-299.

Souza, P. M., Fornazier, A., Ponciano, N. J. \& Gomes Ney, M. (2011), 'Agricultura familiar versus agricultura não-familiar: uma análise das diferenças nos financiamentos concedidos no período de 1999 a 2009', Revista Econômica do Nordeste 42(01), 105-124.

Souza, P. M., Gomes Ney, M., Ponciano, N. J. \& Fornazier, A. (2014), 'Análise das fontes de mudanças na distribuição regional do Pronaf-crédito, no período de 1999 a 2011', Estudos, Sociedade e Agricultura 22(1), 237-254.

Tilman, D., Cassman, K. G., Matson, P. A., Naylor, R. \& Polasky, S. (2002), 'Agricultural sustainability and intensive production practices', $\mathrm{Na}$ ture 418, 671- 677 .

Van Calker, K., Berentsen, P. M., Giesen, G. W. J. \& Huirne, R. B. M. (2005), 'Identifying and ranking attributes that determine sustainabilly in Dutch dairy farming', Agriculture and Human Values 22, 53-63.

Vilain, L. (2008), La méthode IDEA, indicateurs de durabilitédês exploitations agricoles, 3 ed. Dijon: Educagri.

Waas, T., Hugé, J., Verbruggen \& Wrigh, T. (2011), 'Sustainable Development: A bird's eye view', Sustainability 3(10), 1637-1661.

White, M. A. (2013), 'Sustainability: I know it when I see it', Ecological Economics 86, 213-217.

Zaccagnini, M. E. (2001), Analytic framework for assessing factors that influence sustainability of uses of wild living natural resources, The International Union for Conservation of Nature - IUCN. 


\section{Apêndice}

Tabela 8: Variáveis aplicadas na composição do Índice de Sustentabilidade Agrícola de beneficiários e não beneficiários do PRONAF na microrregião do Vale do Médio Curu, no Estado do Ceará

\begin{tabular}{|c|c|}
\hline Índices e indicadores & |Variáveis e sua Operacionalização \\
\hline \multicolumn{2}{|l|}{ Índice da Gestão Ambiental } \\
\hline \multirow{5}{*}{$\begin{array}{l}\text { Indicador de Práticas } \\
\text { de Preparo de Solo }\end{array}$} & Faz desmatamento \\
\hline & \begin{tabular}{|l|} 
Faz queimada \\
\end{tabular} \\
\hline & Usa trator \\
\hline & Usa grade \\
\hline & Usa arado \\
\hline \multirow{4}{*}{$\begin{array}{l}\text { Indicador de Práticas } \\
\text { de Plantio }\end{array}$} & Usa plantio direto \\
\hline & Faz rotação culturas \\
\hline & Usa esterco \\
\hline & $\begin{array}{l}\text { Usa fertilizante. Se sim, usa fertilizante em quanti- } \\
\text { dade maior do que a recomendada; usa fertilizante na } \\
\text { quantidade recomendada }\end{array}$ \\
\hline \multirow{2}{*}{$\begin{array}{l}\text { Indicador de Práticas } \\
\text { de Pós-Plantio }\end{array}$} & Faz capina manual \\
\hline & Usa herbicida \\
\hline \multirow{3}{*}{$\begin{array}{l}\text { Indicador de Práticas de } \\
\text { Combate às Pragas }\end{array}$} & $\begin{array}{l}\text { Métodos combate pragas: não usa nada; usa produto } \\
\text { químico; }\end{array}$ \\
\hline & Frequência de uso: mais 2 vezes; duas vezes; uma vez \\
\hline & \begin{tabular}{|l|} 
Usa defensivo \\
\end{tabular} \\
\hline \multirow{3}{*}{$\begin{array}{l}\text { Indicador dos Serviços de } \\
\text { Assistência Técnica }\end{array}$} & Recebimento de assistência técnica \\
\hline & $\begin{array}{l}\text { Forma recebimento assistência técnica: em grupo; In- } \\
\text { dividual. }\end{array}$ \\
\hline & $\begin{array}{l}\text { Frequência no Recebimento de Assist. Técnica: mais } \\
\text { de } 2 \text { meses, bimensalmente; mensalmente }\end{array}$ \\
\hline \multicolumn{2}{|c|}{ Îndice da Gestão Econômica } \\
\hline \multirow{5}{*}{$\begin{array}{l}\text { Indicador de Organização } \\
\text { da Propriedade }\end{array}$} & Mantém as mesmas culturas \\
\hline & \begin{tabular}{|l|} 
Diversificou a produção \\
\end{tabular} \\
\hline & \begin{tabular}{|l|} 
Melhorou qualidade produção \\
\end{tabular} \\
\hline & \begin{tabular}{|l} 
O chefe de família trabalha mais \\
\end{tabular} \\
\hline & O Trabalho ficou mais fácil \\
\hline $\begin{array}{l}\text { Indicador de Eficiência } \\
\text { Financeira }\end{array}$ & $\begin{array}{l}\text { Receita Agrícola por ha: RA/ (ha) }<\mathrm{R} \$ 2.000,00 ; \mathrm{R} \$ \\
2.000,00 \leq \mathrm{RA} / \text { (ha) }<\mathrm{R} \$ 4.000,00 ; \mathrm{R} \$ 4.000,00 \leq \mathrm{RA} / \\
\text { (ha) }<\mathrm{R} \$ 6.000,00 ; \mathrm{RA} / \text { (ha) } \geq \mathrm{R} \$ 6.000,00\end{array}$ \\
\hline \multirow{2}{*}{$\begin{array}{l}\text { Indicador de Resiliência } \\
\text { Econômica }\end{array}$} & $\begin{array}{l}\text { Em caso de seca ou perda parcial da produção, sua } \\
\text { opção é: abandonar a agricultura; solicitar ajuda aos } \\
\text { familiares; Pedir ajuda a associação ou sindicato; Re- } \\
\text { correr ao Programa Garantia Safra }\end{array}$ \\
\hline & $\begin{array}{l}\text { A sua garantia contra dificuldades ou adversidades cli- } \\
\text { máticas é: nenhuma; poupança pessoal; diversificação } \\
\text { da produção }\end{array}$ \\
\hline
\end{tabular}


Tabela 8: Variáveis aplicadas na composição do Índice de Sustentabilidade Agrícola de beneficiários e não beneficiários do PRONAF na microrregião do Vale do Médio Curu, no Estado do Ceará (continuação)

\begin{tabular}{l|l}
\hline Índices e indicadores & Variáveis e sua Operacionalização \\
\hline \multicolumn{2}{|l}{ Índice da Gestão Social } \\
\hline $\begin{array}{l}\text { Indicador de Confiança } \\
\text { Institucional }\end{array}$ & $\begin{array}{l}\text { Você confia: políticos; polícia; dirigentes de associa- } \\
\text { ções/sindicatos }\end{array}$ \\
\hline \multirow{3}{*}{$\begin{array}{l}\text { Indicador de Organização } \\
\text { de Mercados }\end{array}$} & $\begin{array}{l}\text { A comercialização da produção se dá: na propriedade, } \\
\text { para consumidores; levam diretamente à feira livre; } \\
\text { na propriedade, para comerciantes; através de associ- } \\
\text { ação ou cooperativa }\end{array}$ \\
\hline \multirow{4}{*}{$\begin{array}{l}\text { Indicador de Sentimento } \\
\text { de Pertencimento }\end{array}$} & $\begin{array}{l}\text { Em caso de necessidade, confia que amigos vão poder } \\
\text { ajudá-lo? }\end{array}$ \\
\cline { 2 - 2 } & Você costuma ajudar amigos em dificuldades? \\
\cline { 2 - 2 } $\begin{array}{l}\text { Você e seus amigos comemoram juntos as datas festi- } \\
\text { vas? }\end{array}$ \\
\hline $\begin{array}{l}\text { Indicador de Reforço de } \\
\text { Laços e Valores }\end{array}$ & Convive bem com pessoas de outras religiões? \\
\cline { 2 - 2 } $\begin{array}{l}\text { Indicador de Participação } \\
\text { Social em Defesa }\end{array}$ & $\begin{array}{l}\text { Participa de movimentos em defesa de seus interesses, } \\
\text { como: Concessão de crédito; recebimento de assistên- } \\
\text { cia técnica; acesso a programas governo. }\end{array}$ \\
\cline { 2 - 2 } seus Interesses & $\begin{array}{l}\text { Participa de eleição de dirigentes de associação, sindi- } \\
\text { cato ou cooperativa? }\end{array}$ \\
\hline
\end{tabular}

Fonte: Elaboração dos autores 